\title{
Three-Dimensional Ventral Approach with the Modified Liver- Hanging Maneuver During Laparoscopic Right Hemihepatectomy
}

\author{
Ji Hoon Kim, MD
}

Department of Surgery, College of Medicine, Eulji University, Eulji University Hospital, Daejeon, Republic of Korea

\begin{abstract}
Background. The ventral approach differs completely from the caudal approach because of differences in surgical views and the direction of the parenchymal transection. ${ }^{1-4}$ A three-dimensional (3D) laparoscopy provides the advantages of better depth perception and spatial orientation. ${ }^{5,6}$ We present a 3D ventral approach with the modified liver-hanging maneuver during laparoscopic right hemihepatectomy (LRH).

Methods. This was a case of a 78-year-old woman with a $4 \mathrm{~cm}$ sized cystic tumor located at the right hemiliver. A 3D flexible laparoscope (Olympus Medical Systems Corp., Tokyo, Japan) was used to provide a bird's-eye view of the surgical field similar to that in an open approach. In the early phase, parenchymal transection was initiated in the cranioventral area of the liver. The liver parenchyma was transected in a ventral-to-dorsal direction. The segment $\mathrm{V}$ hepatic vein was dissected and ligated after identifying the main root of the middle hepatic vein. In the late phase, the dorsal area of the liver around the inferior vena cava and the segment VIII hepatic vein were dissected and ligated using the hanging technique. ${ }^{7,8}$

Results. The operation time was $240 \mathrm{~min}$, with an estimated blood loss of $70 \mathrm{~mL}$. Total pringle time was $30 \mathrm{~min}$. Final pathologic diagnosis was a $4.0 \mathrm{~cm}$ sized mucinous cystic neoplasm with low-grade dysplasia. The patient was discharged on postoperative day 7 without any complications.
\end{abstract}

Electronic supplementary material The online version of this article (https://doi.org/10.1245/s10434-019-07384-x) contains supplementary material, which is available to authorized users.

(C) Society of Surgical Oncology 2019

First Received: 12 January 2019;

Published Online: 23 April 2019

J. H. Kim, MD

e-mail: asist10@hanmail.net
Conclusion. The 3D ventral approach with the modified liver-hanging maneuver in LRH is a feasible and useful technique because it resembles open right hemihepatectomy with respect to the surgical concept.

DISCLOSURES Dr. Ji Hoon Kim has no conflicts of interest or financial ties to disclose.

INFORMED CONSENT The patient received an explanation of the procedure and provided informed consent.

ETHICAL APPROVAL This study was approved by the Institutional Review Board at our institute.

\section{REFERENCES}

1. Tomishige $\mathrm{H}$, Morise Z, Kawabe N, et al. Caudal approach to pure laparoscopic posterior sectionectomy under the laparoscopyspecific view. World J Gastrointest Surg. 2013;5:173-177.

2. Ogiso S, Nomi T, Araki K, et al. Laparoscopy-specific surgical concepts for hepatectomy based on the laparoscopic caudal view: a key to reboot surgeons' minds. Ann Surg Oncol. 2015;22:327-333.

3. Kim JH. Laparoscopy-specific ventral approach in laparoscopic hemihepatectomy. J Surg Oncol. 2017;116:159-163.

4. Kim JH. Ventral approach to the middle hepatic vein during laparoscopic hemihepatectomy. Ann Surg Oncol. 2019;26:290.

5. Smith R, Schwab K, Day A, et al. Effect of passive polarizing three-dimensional displays on surgical performance for experienced laparoscopic surgeons. Br J Surg. 2014;101:1453-1459.

6. Kawai T, Goumard C, Jeune F, et al. 3D vision and maintenance of stable pneumoperitoneum: a new step in the development of laparoscopic right hepatectomy. Surg Endosc. 2018;32:3706-3712.

7. Kim JH, Ryu DH, Jang LC, Choi JW. Lateral approach liver hanging maneuver in laparoscopic anatomical liver resections. Surg Endosc. 2016;30:3611-3617.

8. Kim JH. Pure laparoscopic right hepatectomy using modified liver hanging maneuver: technical evolution from caudal approach toward ventral approach. J Gastrointest Surg. 2018;22:1343-1349.

Publisher's Note Springer Nature remains neutral with regard to jurisdictional claims in published maps and institutional affiliations. 